\title{
Relationship between Lifestyle, Quality of Sleep, and Daytime Drowsiness of Nursing Students of University A
}

\author{
Miki Sato', Hirokazu Ito², Hiroko Sugimoto³ ${ }^{3}$, Tetsuya Tanioka², Yuko Yasuhara², Rozzano Locsin'2, \\ Beth King ${ }^{4}$
}

${ }^{1}$ Department of Nursing, Faculty of Nursing, Shikoku University Faculty of Nursing, Tokushima, Japan

${ }^{2}$ Department of Nursing, Institute of Biomedical Sciences, Tokushima University, Tokushima, Japan

${ }^{3}$ Department of Nursing Outcome Management, Graduate School, Tokushima University, Tokushima, Japan

${ }^{4}$ Christine E. Lynn College of Nursing, Florida Atlantic University, Boca Raton, USA

Email:msato@shikoku-u.ac.jp

How to cite this paper: Sato, M., Ito, H., Sugimoto, H., Tanioka, T., Yasuhara, Y., Locsin, R. and King, B. (2017) Relationship between Lifestyle, Quality of Sleep, and Daytime Drowsiness of Nursing Students of University A. Open Journal of Psychiatry, 7, 61-70.

http://dx.doi.org/10.4236/ojpsych.2017.71006

Received: November 9, 2016

Accepted: January 8, 2017

Published: January 11, 2017

Copyright $\odot 2017$ by authors and Scientific Research Publishing Inc. This work is licensed under the Creative Commons Attribution International License (CC BY 4.0).

http://creativecommons.org/licenses/by/4.0/

(c) (i) Open Access

\begin{abstract}
The harmful effects of technological devices, including smart phones have been increasingly suspected among university students; bedtimes have become increasingly later at night, and leisure activities often extend through the night. Likewise, availability and need of increasing part-time job hours have been considered. The purpose of this research was to determine the relationship among lifestyles, quality of sleep, and daytime drowsiness of nursing students of University A. The research was conducted in June 2015, when student life rhythms were considered stable after two months of lectures. Responses with missing values or with inappropriate answers were excluded. Of the data collected from 96 respondents, only 71 were acceptable. The survey focused on lifestyle, daytime sleepiness (using ESS: Epworth Sleepiness Scale) and quality of subjective sleep (using the PSQI: Pittsburgh Sleep Quality Index). Approval was obtained from the Research Ethics Committee of Shikoku University. While in this study, more than half (63.4\%) of the students had poor quality of sleep, however, there was no relationship between their quality of sleep and daytime drowsiness, or between their lifestyles and the quality of sleep. These findings suggest that while university students' use of technological devices is suspected to influence on sleep deprivation and consequent daytime drowsiness, the findings did not provide the evidence.
\end{abstract}

\section{Keywords}

University Students, Lifestyle, Quality of Sleep, Drowsiness at Daytime

\section{Introduction}

A longstanding unsound lifestyle is thought to be involved in the onset and develop- 
ment of diseases, including diabetes, hypertension and depression [1] [2] [3]. Lifestyle diseases are not only the biggest factor obstructing a healthy life-span, but they also adversely affect the national health expenditure [4]. It is said that lifestyle diseases can be prevented by maintaining a well-balanced diet, moderate exercise and sleep, and abstaining from smoking [5] [6] [7].

Recent studies report that sleeping disorders can cause the decrease of glucose tolerance and the increase of appetite [8]. Recent studies report that sleeping disorders can cause the decrease of glucose tolerance and the increase of appetite [8]. Also, it suggests that combinations involving physical inactivity, prolonged sitting, and/or long sleep duration, and smoking and high alcohol intake had the strongest associations with allcause mortality and increase in the risk of various lifestyle diseases [9]. Approximately $20 \%$ of adults are said to have sleeping disorders [10]. Early diagnosis and treatment of sleep disorder is important in obesity prevention [11]. Sleep deprivation increases insulin resistance and may increase the risk of the onset of Type 2 diabetes [12]. Moreover, many patients with Type 2 diabetes have insomnia [13]. Analyzing the quality of sleep of hospitalized patients with Type 2 diabetes using electroencephalograph [14], has indicated that if $\mathrm{HbAlc}$ increased or worsened, poor glycemic control was independently associated with poor quality of sleep as represented by decrease of REM sleep latency.

Sleep should be evaluated not only by the length of time but also by the patients' subjective evaluation, leading to the screening of sleep problems [12] [15], the risk factors of lifestyle diseases, and autonomic nervous disorder.

The Pittsburgh Sleep Quality Index (PSQI) [16] is valued as a reliable index that can easily and qualitatively measure sleep disorders, and assess sleep quality and disturbances over a one-month time interval. The PSQI is often used because the questions to assess the qualitative sleeping condition are prepared in a simplified manner [17] [18] [19].

Generally, sleep disturbance results interfere with daily life activities due to inability to sustain sleep quality and daytime wakefulness [20]. However, the Epworth Sleepiness Scale (ESS) [21] measures subjective transient drowsiness during the daytime. The ESS is used globally and can be used not only for the measurement of drowsiness among patients having sleeping problems, but also for ordinary people [22]. Using the PSQI and ESS questionnaires to evaluate sleep quality and daytime sleepiness provides a reliable and valid measure for subjective sleep quality [23].

Sleep disturbances in adolescence have received significant attention because of their high prevalence and the negative health outcomes [24]. The sleep of university students can be disruptive because of leisure activities and part-time jobs at night, and as a result they go to bed late at night [25]. In addition, the use of electronic devices, including smart phones, has been increasingly identified as harmful [26]. The evidence indicates that lifestyle affects diabetes and quality of sleep, and in order to prevent lifestyle diseases during the early years, it is necessary to acquire a healthy lifestyle. Thus, it is important to grasp the relationship between daily lifestyle and sleep.

The purpose of this research was to clarify the relationship among lifestyle, quality of sleep, and daytime drowsiness of nursing students in University A. 


\section{Materials and Methods}

\subsection{Subjects}

There were 96 subjects in this study comprised of students in their third year in University A. The inclusion criterion was that subjects must be university students. Any students who were unable to answer the questionnaire and had physical/psychiatric disorders were excluded.

\subsection{Study Period}

The research was conducted in June 2015, two months after the beginning of the school year and the student's life rhythms were considered more stable.

\subsection{Measures}

The lifestyle measures were based on previous research studies [27]. Students were asked to provide the following data: gender, age, whether they live alone or not, whether they have breakfast or not, the time from evening meals to bedtime, whether or not they take naps, have a part-time job or not, do regular exercise or not, their bathing schedule, whether they listen to music and watch TV, use smart phones before bedtime or not, whether they are awakened by a smart phone alarm, body height and weight (BMI: Body Mass Index), changes of body weight within the past year, drinking, and the existence or none existence of diabetes and hypertension within their family members.

The student's quality of sleep was evaluated using the PSQI and, at the same time, the degree of their drowsiness during the daytime was evaluated using the Japanese version of the Epworth Sleepiness Scale (ESS).

In this research, the cut-off score of $>6$ would mean poor sleep quality in the PSQI [28], and the cut-off score of $>11$ points indicated the possibility of daytime sleepiness based on the ESS [29], respectively.

For the quantitative variables, Spearman's rank correlation coefficient was calculated. For measuring the lifestyles, the data were divided into present or not present. For the PSQI data was divided into good or poor, and for ESS was divided into present not or present groups, respectively. For the qualitative variables, a cross-tabulation analysis was conducted and the related data were analyzed by Person's $\chi^{2}$ test, Fisher's exact test and $\Phi$-coefficient.

\subsection{Ethical Consideration}

This research was conducted with the approval of the Ethics Committee of the Shikoku University in Tokushima, Japan. Researchers explained the purpose, content and method of the research study to prospective subjects, both verbally and in writing. Consent to participate was assumed when the questionnaire forms were returned by the subjects. Furthermore, it was also explained to prospective subjects that non-participation would not disadvantage them in any way. Anonymity was assured. No names or other identifying marks were required to participate in the study and the subjects were assured that publication of the results would only be made as aggregate data. 


\section{Results}

The responses with missing values or inappropriate answers were excluded from the responses collected from 96 respondents. With this exclusion, the number of valid responses were $71(74 \%)$, of which there were 12 men (16.9\%) and 59 women $(83.1 \%)$. Their average age was $20.4 \pm 1.9$, BMI was $20.92 \pm 2.55 \mathrm{~kg} / \mathrm{m}^{2}$, PSQI was $7.56 \pm 3.90$ points and ESS was $8.51 \pm 3.81$ (see Table 1).

There was no significant relationship among the following: a) Time from evening meals to bedtime, b). BMI, c). PSQI and d). ESS scores (Table 2).

Regarding the relationship among lifestyles, PSQI and ESS scores, those subjects whose family members did not have Type 2 diabetes, had significantly higher scores in the PSQI ( $\varphi$-coefficient $=0.25, \mathrm{p}<0.05)$. Forty-five subjects $(63.4 \%)$ among 71 subjects had 6 points or more in PSQI. However, no significant relationships were found among the other items (see Table 3).

\section{Discussion}

The findings of this study yielded no significant relationship among the time from evening meals to bedtime, BMI, PSQI score and ESS score. However, PSQI score was $7.56 \pm 3.9$ points, more than $60 \%$ of students were more than six points that indicating poor quality of sleep.

In previous research studies of more than 1,000 university students using PSQI [30], it was reported that $79.2 \%$ exceeded the cutoff point indicating poor sleep quality, and showed problems of chronic sleep deprivation, rhythmic irregularity between sleep and wakefulness, and that their bedtime became later as they advanced in their grade levels.

Table 1. Basic characteristics of this subject.

\begin{tabular}{llcc}
\hline \multicolumn{1}{c}{ Age } & Men & $20.37 \pm 1.91$ & (Yrs.) \\
\multicolumn{1}{c}{ Sex } & Women & 12 & \\
& 59 & \\
Time from Evening Meals to Bedtime & $5.26 \pm 1.26$ & $($ Hours $)$ \\
Body Height & $1.60 \pm 0.68$ & $(\mathrm{M})$ \\
Body Weight & $53.93 \pm 8.07$ & $(\mathrm{Kg})$ \\
BMI: Body Mass Index & $20.92 \pm 2.55$ & $\left(\mathrm{Kg} / \mathrm{m}^{2}\right)$ \\
PSQI: Pittsburgh Sleep Quality Index & $7.56 \pm 3.90$ & $($ Points $)$ \\
ESS: Epworth Sleepiness Scale & $8.51 \pm 3.81$ & $($ Points $)$ \\
\hline
\end{tabular}

Table 2. Relationship among the time from evening meals to bedtime, BMI, PSQI and ESS scores.

\begin{tabular}{|c|c|c|c|c|c|c|}
\hline \multirow[b]{2}{*}{ Time from Evening Meals to Bedtime } & \multicolumn{2}{|c|}{ BMI } & \multicolumn{2}{|c|}{ PSQI scores } & \multicolumn{2}{|c|}{ ESS scores } \\
\hline & -0.176 & n.s. & -0.129 & n.s. & -0.003 & n.s. \\
\hline BMI: Body Mass Index & & & 0.135 & n.s. & -0.094 & n.s. \\
\hline PSQI: Pittsburgh Sleep Quality Index & & & & & 0.135 & n.s. \\
\hline
\end{tabular}

※Spearman's rank correlation coefficient, n.s.: not significant. 
Table 3. Relationship among lifestyle, disease history of family, PSQI and ESS scores.

\begin{tabular}{|c|c|c|c|c|c|c|c|c|c|c|c|c|c|c|c|c|c|}
\hline & & \multicolumn{4}{|c|}{ PSQI } & \multicolumn{12}{|c|}{ ESS } \\
\hline & & \multicolumn{2}{|c|}{$\begin{array}{c}\text { Low } \\
\text { (less than 6) }\end{array}$} & \multicolumn{2}{|c|}{$\begin{array}{c}\text { High } \\
\text { (6 or more) }\end{array}$} & \multirow[t]{2}{*}{$x^{2}$} & \multirow[t]{2}{*}{$\mathrm{p}$} & & \multirow[t]{2}{*}{$\varphi$} & \multicolumn{2}{|c|}{$\begin{array}{l}\text { Low } \\
\text { (less than 11) }\end{array}$} & \multicolumn{2}{|c|}{$\begin{array}{c}\text { High } \\
\text { (11 or more) }\end{array}$} & \multirow[t]{2}{*}{$x^{2}$} & \multirow[t]{2}{*}{$\mathrm{p}$} & \multirow{2}{*}{\multicolumn{2}{|c|}{$\varphi$}} \\
\hline & & $\mathrm{n}$ & $(\%)$ & $\mathrm{n}$ & $(\%)$ & & & & & $\mathrm{n}$ & $(\%)$ & $\mathrm{n}$ & $(\%)$ & & & & \\
\hline LT (Living Together) & Live alone & 15 & $(21.1)$ & 21 & $(29.6)$ & 0.80 & 0.37 & n.s. & 0.11 & 23 & $(32.4)$ & 13 & $(18.3)$ & 1.50 & 0.22 & n.s. & -0.15 \\
\hline \multirow{3}{*}{ Breakfast } & Live with parents & 11 & $(15.5)$ & 24 & $(33.8)$ & & & & & 27 & $(38.0)$ & 8 & $(11.3)$ & & & & \\
\hline & Take every day & 21 & $(29.6)$ & 39 & $(54.9)$ & 0.44 & $0.37^{\mathrm{a})}$ & n.s. & -0.08 & 44 & $(62.0)$ & 16 & $(22.5)$ & 1.58 & $0.18^{\mathrm{a})}$ & n.s. & 0.15 \\
\hline & $\begin{array}{l}\text { Do not take } \\
\text { every day }\end{array}$ & 5 & $(7.0)$ & 6 & $(8.5)$ & & & & & 6 & $(8.5)$ & 5 & $(7.0)$ & & & & \\
\hline \multirow[t]{2}{*}{ Naps } & Do & 6 & $(8.5)$ & 9 & $(12.7)$ & 0.09 & 0.76 & n.s. & 0.04 & 9 & $(12.7)$ & 6 & $(8.5)$ & 0.99 & 0.32 & n.s. & -0.12 \\
\hline & Do not & 20 & $(28.2)$ & 36 & $(50.7)$ & & & & & 41 & $(57.7)$ & 15 & $(21.1)$ & & & & \\
\hline \multirow[t]{2}{*}{ Part-time jobs } & Do & 18 & $(25.4)$ & 35 & $(49.3)$ & 0.64 & 0.43 & n.s. & -0.10 & 35 & $(49.3)$ & 18 & $(25.4)$ & 1.93 & $0.14^{\mathrm{a})}$ & n.s. & -0.17 \\
\hline & Do not & 8 & $(11.3)$ & 10 & $(14.1)$ & & & & & 15 & $(21.1)$ & 3 & $(4.2)$ & & & & \\
\hline \multirow[t]{2}{*}{ Regularly exercise } & Do & 16 & $(22.5)$ & 28 & $(39.4)$ & 0.00 & 0.95 & n.s. & -0.01 & 31 & $(43.7)$ & 13 & $(18.3)$ & 0.00 & 0.99 & n.s. & 0.00 \\
\hline & Do not & 10 & $(14.1)$ & 17 & $(23.9)$ & & & & & 19 & $(26.8)$ & 8 & $(11.3)$ & & & & \\
\hline \multirow[t]{2}{*}{ Way of bath } & Shower & 15 & $(21.1)$ & 24 & $(33.8)$ & 0.13 & 0.72 & n.s. & 0.04 & 26 & $(36.6)$ & 13 & $(18.3)$ & 0.59 & 0.44 & n.s. & -0.09 \\
\hline & Bathtub & 11 & $(15.5)$ & 21 & $(29.6)$ & & & & & 24 & $(33.8)$ & 8 & $(11.3)$ & & & & \\
\hline \multirow[t]{2}{*}{$\begin{array}{l}\text { Listen to music } \\
\text { and to watch TV }\end{array}$} & Do & 13 & $(18.3)$ & 22 & $(31.0)$ & 0.01 & 0.93 & n.s. & 0.01 & 26 & $(36.6)$ & 9 & $(12.7)$ & 0.50 & 0.48 & n.s. & 0.08 \\
\hline & Do not & 13 & $(18.3)$ & 23 & $(32.4)$ & & & & & 24 & $(33.8)$ & 12 & $(16.9)$ & & & & \\
\hline \multirow[t]{2}{*}{$\begin{array}{l}\text { Use of smart } \\
\text { phone before } \\
\text { bedtime }\end{array}$} & Do & 20 & $(28.2)$ & 41 & $(57.7)$ & 2.74 & $0.10^{\mathrm{a})}$ & n.s. & -0.20 & 41 & $(57.7)$ & 20 & $(28.2)$ & 2.14 & $0.14^{\mathrm{a})}$ & n.s. & -0.17 \\
\hline & Do not & 6 & $(8.5)$ & 4 & $(5.6)$ & & & & & 9 & $(12.7)$ & 1 & $(1.4)$ & & & & \\
\hline $\begin{array}{l}\text { Awakening by } \\
\text { smart phone } \\
\text { during bedtime }\end{array}$ & Not every day & 24 & $(33.8)$ & 36 & $(50.7)$ & 1.91 & $0.15^{\mathrm{a})}$ & n.s. & -0.16 & 43 & $(60.6)$ & 17 & $\begin{array}{l}(5.6) \\
(23.9)\end{array}$ & 0.29 & $0.42^{\mathrm{a})}$ & n.s. & -0.06 \\
\hline $\begin{array}{l}\text { Changes of body } \\
\text { weight within }\end{array}$ & Existence & 16 & $(22.5)$ & 23 & $(32.4)$ & 0.72 & 0.40 & n.s. & 0.10 & 27 & $(38.0)$ & 12 & $(16.9)$ & 0.06 & 0.81 & n.s. & -0.03 \\
\hline the past year & None existence & 10 & $(14.1)$ & 22 & $(31.0)$ & & & & & 23 & $(32.4)$ & 9 & $(12.7)$ & & & & \\
\hline \multirow[t]{2}{*}{ Drinking } & Do & 18 & $(25.4)$ & 33 & $(46.5)$ & 0.14 & 0.71 & n.s. & -0.04 & 33 & $(46.5)$ & 18 & $(25.4)$ & 2.84 & $0.08^{\mathrm{a})}$ & n.s. & -0.20 \\
\hline & Do not & 8 & $(11.3)$ & 12 & $(16.9)$ & & & & & 17 & $(23.9)$ & 3 & $(4.2)$ & & & & \\
\hline $\begin{array}{l}\text { Existence of diabetes } \\
\text { within their }\end{array}$ & Existence & 12 & $(16.9)$ & 10 & $(14.1)$ & 4.41 & 0.04 & * & 0.25 & 18 & $(25.4)$ & 4 & $(5.6)$ & 1.99 & $0.13^{\text {a) }}$ & n.s. & 0.17 \\
\hline family members & None existence & 14 & $(19.7)$ & 35 & $(49.3)$ & & & & & 32 & $(45.1)$ & 17 & $(23.9)$ & & & & \\
\hline $\begin{array}{c}\text { Existence of } \\
\text { hypertension within }\end{array}$ & Existence & 20 & $(28.2)$ & 26 & $(36.6)$ & 2.65 & 0.10 & n.s. & 0.19 & 33 & $(46.5)$ & 13 & $(18.3)$ & 0.11 & 0.74 & n.s. & 0.04 \\
\hline their family members & None existence & 6 & $(8.5)$ & 19 & $(26.8)$ & & & & & 17 & $(23.9)$ & 8 & $(11.3)$ & & & & \\
\hline
\end{tabular}

Pearson's $\chi^{2}$ test, a): Fisher's exact test, n.s.: not significant. 
University students declared that because they have relatively enough free time and are in an environment where they control time by themselves, their bedtimes become later by increasing leisure activities and performing part-time jobs at night [31]. Previous studies indicates that lifestyle affects diabetes and quality of sleep [12] [13] [14], and furthermore, it was reported that university students' sleep problems and wakefulness adversely affect their academic achievement [32]. The disturbance of sleep leads to not only mental and physical problems, but also adversely affects academic achievement.

According to McHill et al., eating evening meals late at night increases the risk of obesity and body weight gain [33]. Because the improvement of lifestyle decreases the risk of diabetes [7] [34], it is important for university students to enhance the quality of their sleep which can lead to an improvement of their lifestyle.

For drowsiness, the ESS score of about $30 \%$ of students was more than 11 points that indicate daytime sleepiness, but it had no significant relationship with lifestyle. This may be because the PSQI evaluated the students' own sleep for the past month, whereas the ESS only assessed for drowsiness on the day of the survey. Therefore, it is underscored that in order to investigate drowsiness during the daytime, it is necessary to survey the ESS perhaps several times a month, for at least the same period as when PSQI is surveyed.

No significant relationship was found between sleep and media devices such as "Listen to music and to watch TV", "Use of smart phone before bedtime", and "Awakening by smart phone during bedtime" in this study.

But other studies have indicated that people who were reading their iPads secreted less melatonin and took more time to enter the sleep cycle at night and their REM sleep time was shorter than those who were reading paper media [35]. In another study of men and women in the United Kingdom [36], the sleep-onset time of those who often used MP3 players and video games were much later, and their risks of early waking, nightmares and sleepwalking were much higher as well.

A significant finding was the relationship between lifestyle and the decreased scores on the PSQI of subjects whose family members did not have diabetes. It suggested that those subjects had poor sleep quality. However, this result does not represent other studies which indicate that persons with diabetes suffer from sleep deprivation indicating that there is a relationship between diabetes and sleep [37] [38]. When analyzing the results the genetic factor of diabetes must be considered [39]. Another factor to consider is the age of the subjects. In this research, the subjects were university students between the ages of $20.37 \pm 1.91$, and diabetes may not yet be a relevant factor.

\section{Limitations}

The small number of subjects in this study was a limitation and may have impacted the results. The relationship among lifestyle, PSQI and ESS, found that the PSQI score of those whose families did not have Type 2 diabetes, was significantly higher. These results indicate a need for a future research study which utilizes objective measurements, by targeting students who were judged to have poor quality of sleep and using an actigraph and heart rate variability analysis, promoting the behavioral transformation for 
the improvement of the quality of life particularly of students who use technological devices and decrease the risks of lifestyle diseases. Moreover, this data was based on the sleep status of university third year grade students only. Therefore, it may be necessary to investigate the sleep status of other students. PSQI is for evaluating sleep quality during the past month. Therefore, there is a possibility that completion of school requirements at night may have imposed on students' sleep status.

\section{Conclusion}

In this study, more than half (63.4\%) of the students had poor quality of sleep, however, there was no relationship between their quality of sleep and daytime drowsiness, or between their lifestyles and the quality of sleep. These findings suggest that while university students' uses of technological devices are suspected influences to poor quality of sleep and consequent daytime drowsiness, the findings haven't provided the evidence.

\section{Acknowledgements}

We would like to express our deep gratitude to the subjects of this study, and to the members of Professor Tanioka's laboratory.

\section{Conflict of Interest}

All of the co-authors declare that they have no direct conflict of interest or grant support that is directly related to the content of the study.

\section{References}

[1] Gangwisch, J.E., Heymsfield, S.B., Boden-Albala, B., Buijs, R.M., Kreier, F., Pickering, T.G, Rundle, A.G., Zammit, G.K. and Malaspina, D. (2006) Short Sleep Duration as a Risk Factor for Hypertension: Analyses of the First National Health and Nutrition Examination Survey. Hypertension, 47, 833-839. https://doi.org/10.1161/01.HYP.0000217362.34748.e0

[2] Gangwisch, J.E., Malaspina, D., Posner, K., Babiss, L.A., Heymsfield, S.B., Turner, J.B., Zammit, G.K. and Pickering, T.G. (2010) Insomnia and Sleep Duration as Mediators of the Relationship between Depression and Hypertension Incidence. American Journal of Hypertension, 23, 62-69. https://doi.org/10.1038/ajh.2009.202

[3] Beihl, D.A., Liese, A.D. and Haffner, S.M. (2009) Sleep Duration as a Risk Factor for Incident Type 2 Diabetes in a Multiethnic Cohort. Annals of Epidemiology, 19, 351-357. https://doi.org/10.1016/j.annepidem.2008.12.001

[4] Go, A.S., Mozaffarian, D., Roger, V.L., Benjamin, E.J., Berry, J.D., Blaha, M.J., Dai, S., Ford, E.S., Fox, C.S., Franco, S., Fullerton, H.J., Gillespie, C., Hailpern, S.M., Heit, J.A., Howard, V.J., Huffman, M.D., Judd, S.E., Kissela, B.M., Kittner, S.J., Lackland, D.T., Lichtman, J.H., Lisabeth, L.D., Mackey, R.H., Magid, D.J., Marcus, G.M., Marelli, A., Matchar, D.B., McGuire, D.K., Mohler, E.R., Moy, C.S., Mussolino, M.E., Neumar, R.W., Nichol, G., Pandey, D.K., Paynter, N.P., Reeves, M.J., Sorlie, P.D., Stein, J., Towfighi, A., Turan, T.N., Virani, S.S., Wong, N.D., Woo, D., Turner, M.B., American Heart Association Statistics Committee and Stroke Statistics Subcommittee (2014) Heart Disease and Stroke Statistics-2014 Update: A Report from the American Heart Association. Circulation, 129, 399-410. https://doi.org/10.1161/01.cir.0000442015.53336.12

[5] Diabetes Prevention Program Research Group (2002) Reduction in the Incidence of Type 2 Diabetes with Lifestyle Intervention or Metformin. The New England Journal of Medicine, 346, 393-403. https://doi.org/10.1056/NEJMoa012512 
[6] Knowler, W.C., Fowlerm, S.E., Hamman, R.F., Christophi, C.A., Hoffman, H.J., Brenneman, A.T., Brown-Friday, J.O., Goldberg, R., Venditti, E. and Nathan, D.M., Diabetes Prevention Program Research Group (2009) 10-Year Follow-Up of Diabetes Incidence and Weight Loss in the Diabetes Prevention Program Outcomes Study. The Lancet, 374, 16771686.

[7] Li, G., Zhang, P., Wang, J., Gregg, E.W., Yang, W., Gong, Q., Li, H., Li, H., Jiang, Y., An, Y., Shuai, Y., Zhang, B., Zhang, J., Thompson, T.J., Gerzoff, R.B., Roglic, G., Hu, Y. and Bennett, P.H. (2008) The Long-Term Effect of Lifestyle Interventions to Prevent Diabetes in the China Da Qing Diabetes Prevention Study: A 20-Year Follow-Up Study. The Lancet, 371, 1783-1789. https://doi.org/10.1016/S0140-6736(08)60766-7

[8] Morselli, L., Leproult, R., Balbo, M. and Spiegel, K. (2010) Role of Sleep Duration in the Regulation of Glucose Metabolism and Appetite. Best Practice \& Research Clinical Endocrinology \& Metabolism, 24, 687-702. https://doi.org/10.1016/j.beem.2010.07.005

[9] Ding, D., Rogers, K., van der Ploeg, H., Stamatakis, E. and Bauman, A.E. (2015) Traditional and Emerging Lifestyle Risk Behaviors and All-Cause Mortality in Middle-Aged and Older Adults: Evidence from a Large Population-Based Australian Cohort. PLoS Medicine, 12, e1001917. https://doi.org/10.1371/journal.pmed.1001917

[10] Liu, X., Uchiyama, M., Kim, K., Okawa, M., Shibui, K., Kudo, Y., Doi, Y., Minowa, M. and Ogihara, R. (2000) Sleep Loss and Daytime Sleepiness in the General Adult Population of Japan. Psychiatry Research, 93, 1-11. https://doi.org/10.1016/S0165-1781(99)00119-5

[11] Bocicor, A.E., Buicu, G., Sabau, D., Varga, A., Tilea, I. and Gabos-Grecu, I. (2016) Association between Sleep Disorder and Increased Body Mass Index in Adult Patients. Acta Medica Marisiensis, 62, 221-224. https://doi.org/10.1515/amma-2016-0015

[12] Spiegel, K., Leproult, R. and Van Cauter, E. (1999) Impact of Sleep Debt on Metabolic and Endocrine Function. The Lancet, 354, 1435-1439. https://doi.org/10.1016/S0140-6736(99)01376-8

[13] Skomro, R.P., Ludwig, S., Salamon, E. and Kryger, M.H. (2001) Sleep Complaints and Restless Legs Syndrome in Adult Type 2 Diabetics. Sleep Medicine, 2, 417-422. https://doi.org/10.1016/S1389-9457(01)00110-1

[14] Yoda, K., Inaba, M., Hamamoto, K., Yoda, M., Tsuda, A., Mori, K., Imanishi, Y., Emoto, M. and Yamada, S. (2015) Association between Poor Glycemic Control, Impaired Sleep Quality, and Increased Arterial Thickening in Type 2 Diabetic Patients. PLoS ONE, 10, e0122521. https://doi.org/10.1371/journal.pone.0122521

[15] Kaneita, Y., Uchiyama, M., Yoshiike, N. and Ohida, T. (2008) Associations of Usual Sleep Duration with Serum Lipid and Lipoprotein Levels. Sleep, 31, 645-652.

[16] Buysse, D.J., Reynolds, C.F., Monk, T.H., Berman, S.R. and Kupfer, D.J. (1989) The Pittsburgh Sleep Quality Index: A New Instrument for Psychiatric Practice and Research. Psychiatry Research, 28, 193-213. https://doi.org/10.1016/0165-1781(89)90047-4

[17] Sato, M., Yasuhara, Y., Tanioka, T., Iwasa, Y., Miyake, M., Yasui, T., Tomotake, M., Kobayashi, H. and Locsin, R.C. (2014) Measuring Quality of Sleep and Autonomic Nervous Function in Healthy Japanese Women. Neuropsychiatric Disease and Treatment, 10, 89-96.

[18] Huang, Y., Mai, W., Hu, Y., Wu, Y., Song, Y., Qiu, R., Dong, Y. and Kuang, J. (2011) Poor Sleep Quality, Stress Status, and Sympathetic Nervous System Activation in Nondipping Hypertension. Blood Pressure Monitoring, 16, 117-123. https://doi.org/10.1097/MBP.0b013e328346a8b4

[19] Kung, Y.Y., Yang, C.C., Chiu, J.H. and Kuo, T.B. (2011) The Relationship of Subjective Sleep Quality and Cardiac Autonomic Nervous System in Postmenopausal Women with Insomnia under Auricular Acupressure. Menopause, 18, 638-645. https://doi.org/10.1097/gme.0b013e31820159c1 
[20] Ozdemir, P.G., Boysan, M., Selvi, Y., Yildirim, A. and Yilmaz, E. (2015) Psychometric Properties of the Turkish Version of the Sleep Hygiene Index in Clinical and Non-Clinical Samples. Comprehensive Psychiatry, 59, 135-140. https://doi.org/10.1016/j.comppsych.2015.02.001

[21] Takegami, M., Suzukamo, Y., Wakita, T., Noguchi, H., Chin, K., Kadotani, H., Inoue, Y., Oka, Y., Nakamura, T., Green, J., Johns, M.W. and Fukuhara, S. (2009) Development of a Japanese Version of the Epworth Sleepiness Scale (JESS) Based on Item Response Theory. Sleep Medicine, 10, 556-565. https://doi.org/10.1016/j.sleep.2008.04.015

[22] Johns, M.W. (1993) Daytime Sleepiness, Snoring, and Obstructive Sleep Apnea: The Epworth Sleepiness Scale. Chest, 103, 30-36. https://doi.org/10.1378/chest.103.1.30

[23] Yazdi, Z., Sadeghniiat-Haghighi, K., Zohal, M.A. and Elmizadeh, K. (2012) Validity and Reliability of the Iranian Version of the Insomnia Severity Index. Malaysian Journal of Medical Sciences, 19, 31-36.

[24] Ji, X. and Liu, J. (2016) Subjective Sleep Measures for Adolescents: A Systematic Review. Child: Care, Health and Development, 42, 825-839. https://doi.org/10.1111/cch.12376

[25] Sugita, Y. (2011) University of Life Rhythm and Sleep Problems. Daigaku to Gakusei, 89, 17-23. (In Japanese)

[26] Cain, N. and Gradisar, M. (2010) Electronic Media Use and Sleep in School-Aged Children and Adolescents: A Review. Sleep Medicine, 11, 735-742. https://doi.org/10.1016/j.sleep.2010.02.006

[27] Matsuda, H., Ogawa, N., Tsukada, R., Kodama, Y., Yamazaki, A., Kosako, Y., Miyamoto, H. and Morimoto, M. (2012) Factors That Affect Quality of Sleep in Female University Student. Journal of Japan Society of Nursing Research, 35, 47-55. (In Japanese)

[28] Alsaadi, S.M., McAuley, J.H., Hush, J.M., Bartlett, D.J., Henschke, N., Grunstein, R.R. and Maher, C.G. (2013) Detecting Insomnia in Patients with Low Back Pain: Accuracy of Four Self-Report Sleep Measures. BMC Musculoskeletal Disorders, 14, 196. https://doi.org/10.1186/1471-2474-14-196

[29] Schwegler, K., Klaghofer, R., Nirkko, A.C., Mathis, J., Hersberger, K.E. and Bloch, K.E. (2006) Sleep and Wakefulness Disturbances in Swiss Pharmacy Customers. Swiss Medical Weekly, 136, 149-154.

[30] Yamamoto, R. and Nomura, S. (2009) A Study of Sleep Problems in Undergraduates Using Pittsburgh Sleep Quality Index. Japanese Society of Psychosomatic Medicine, 49, 817-815. (In Japanese)

[31] Bureau of Labor Statistics (2010) American Time Use Survey: Time Use on Average Weekday for Full Time University and College Students. http://www.bls.gov/tus/charts/students.htm

[32] Trockel, M.T., Barnes, M.D. and Egget, D.L. (2010) Health-Related Variables and Academic Performance among First-Year College Students: Implications for Sleep and Other Behaviors. Journal of American College Health, 49, 125-131. https://doi.org/10.1080/07448480009596294

[33] McHill, A.W., Melanson, E.L., Higgins, J., Connick, E., Moehlman, T.M., Stothard, E.R. and Wright, K.P. (2014) Impact of Circadian Misalignment on Energy Metabolism during Simulated Nightshift Work. Proceeding of the National Academy of Sciences of the United States of America, 111, 17302-17307. https://doi.org/10.1073/pnas.1412021111

[34] Shellenberg, E.S., Dryden, D.M., Vandermeer, B., Ha, C. and Korowynk, C. (2013) Lifestyle Interventions for Patients with and at Risk for Type 2 Diabetes: A Systematic Review and Meta-Analysis. Annals of Internal Medicine, 159, 543-551. https://doi.org/10.7326/0003-4819-159-8-201310150-00007

[35] Chang, A.M., Aeschbach, D., Duffy, J.F. and Czeisler, C.A. (2015) Evening Use of Light- 
Emitting eReaders Negatively Affects Sleep, Circadian Timing, and Next-Morning Alertness. Proceeding of the National Academy of Sciences of the United States of America, 112, 1232-1237. https://doi.org/10.1073/pnas.1418490112

[36] Arora, T., Broglia, E., Thomas, G.N. and Taheri, S. (2014) Associations between Specific Technologies and Adolescent Sleep Quantity, Sleep Quality, and Parasomnias. Sleep Medicine, 15, 240-247. https://doi.org/10.1016/j.sleep.2013.08.799

[37] Pallayova, M., Donic, V., Gresova, S., Peregrim, I. and Tomori, Z. (2010) Do Differences in Sleep Architecture Exist between Persons with Type 2 Diabetes and Nondiabetic Controls? Journal of Diabetes Science and Technology, 4, 344-352. https://doi.org/10.1177/193229681000400215

[38] Nakajima, H., Kaneita, Y., Yokoyama, E., Harano, S., Tamaki, T., Ibuka, E., Kaneko, A., Takahashi, I., Umeda, T., Nakaji, S. and Ohida, T. (2007) Association between Sleep Duration and Hemoglobin $\mathrm{A}_{1 \mathrm{c}}$ Level. Sleep Medicine, 9, 745-752. https://doi.org/10.1016/j.sleep.2007.07.017

[39] Li, H., Isomaa, B., Taskinen, M.R., Groop, L. and Tuomi, T. (2000) Consequences of a Family History of Type 1 and Type 2 Diabetes on the Phenotype of Patients with Type 2 Diabetes. Diabetes Care, 23, 589-594. https://doi.org/10.2337/diacare.23.5.589

\section{Submit or recommend next manuscript to SCIRP and we will provide best service for you:}

Accepting pre-submission inquiries through Email, Facebook, LinkedIn, Twitter, etc. A wide selection of journals (inclusive of 9 subjects, more than 200 journals)

Providing 24-hour high-quality service

User-friendly online submission system

Fair and swift peer-review system

Efficient typesetting and proofreading procedure

Display of the result of downloads and visits, as well as the number of cited articles

Maximum dissemination of your research work

Submit your manuscript at: http://papersubmission.scirp.org/

Or contact ojpsych@scirp.org 